\title{
Computational Model of a Lock Filling System
}

US Army Corps

of Engineers ${ }_{\circledast}$

by Richard L. Stockstill

PURPOSE: This Coastal and Hydraulics Engineering Technical Note (CHETN) demonstrates the construction of a three-dimensional (3-D) computational flow model of a lock filling system. A numerical flow model capable of simulating flows in navigation locks will provide an economical tool for detailed evaluation of locks and lock components. A description of the construction, implementation, and evaluation of a 3-D model of a lock filling system is presented. Computational and hydraulic engineering issues regarding implementation are discussed.

BACKGROUND: Whether it is new lock construction, rehabilitation of an existing lock, or operational changes to meet modified project objectives, innovative ideas regarding the filling and emptying of locks are being proposed. The problem is that often these ideas fall outside the U.S. Army Corps of Engineers' lock design guidance, EM 1110-2-1604 (Headquarters, U.S. Army Corps of Engineers 2006). Perhaps some of these ideas, while economically feasible, may not provide the service required for safe navigation through the lock. Currently, the design concept must be carefully evaluated in a physical model, which generally is expensive in terms of both time and money.

The 3-D Navier-Stokes component of the Adaptive Hydraulics (ADH) (http://adh.usace.army.mil/) code has been validated with field data to reproduce large-scale flow features (Stockstill et al. 2005). A numerical flow model of a navigation lock must be capable of simulating the large and small scale flow features found in internal (conduit) flow and freesurface flow found in the approach and chamber. Initial evaluation of the usefulness of ADH applications to hydraulic structures is presented in previous technical notes (Stockstill et al. 2006; Stockstill and Berger 2000).

The Reynolds Averaged Navier-Stokes equations are used to describe the 3-D flow. An algebraic eddy viscosity model is used for turbulence closure. The water-surface location is determined using a moving mesh method. Moving mesh employs space-time finite elements in a manner similar to that presented by Behr (2001).

The equations are discretized using the Galerkin Least-Squares finite element algorithm on tetrahedral elements with sizes often varying over several orders of magnitude. The code is parallelized using Message Passing Interface (MPI), taking advantage of the multiple-processor machines of the Major Shared Resource Center (MSRC), U.S. Army Engineer Research and Development Center, Information Technology Laboratory (ITL). The ADH code is capable of adapting the mesh during flow calculations based on error estimates (Tate et al. 2005).

EVALUATION OF WEBBERS FALLS LOCK: An example is provided with simulation of a navigation lock filling operation. The project was Webbers Falls Lock, located at navigation mile 368.9 on the McClellan-Kerr Arkansas River Navigation System about 5 miles northwest of 
Webbers Falls, OK. A typical lock chamber on the Arkansas River (Figure 1) is nominally $110 \mathrm{ft}$ wide by $600 \mathrm{ft}$ long. The filling and emptying system is a sidewall port system. The normal pool at Webbers Falls Lock and Dam is el ${ }^{1} 487$ and the normal tailwater is el 458 . A general study of lock filling and emptying systems for the Arkansas River system was previously conducted using a physical model (Ables and Boyd 1966).

The model of the 29-ft lift lock is shown in Figure 2. It reproduced approximately $500 \mathrm{ft}$ of the upstream approach, twin sidewall intake manifolds, the lock chamber, valve wells, sidewall ports and culverts. The culvert system consists of 8 -port 7.5 -ft-wide by 10 -ft-tall intake manifolds on either lock wall from which the flow transitions to $12-\mathrm{ft}$ by $12-\mathrm{ft}$ culverts in each wall. Flow is introduced into the lock chamber by 14 ports in each sidewall filling and emptying manifold. Each port is $3.5 \mathrm{ft}$ tall and has a throat width of $2.54 \mathrm{ft}$.

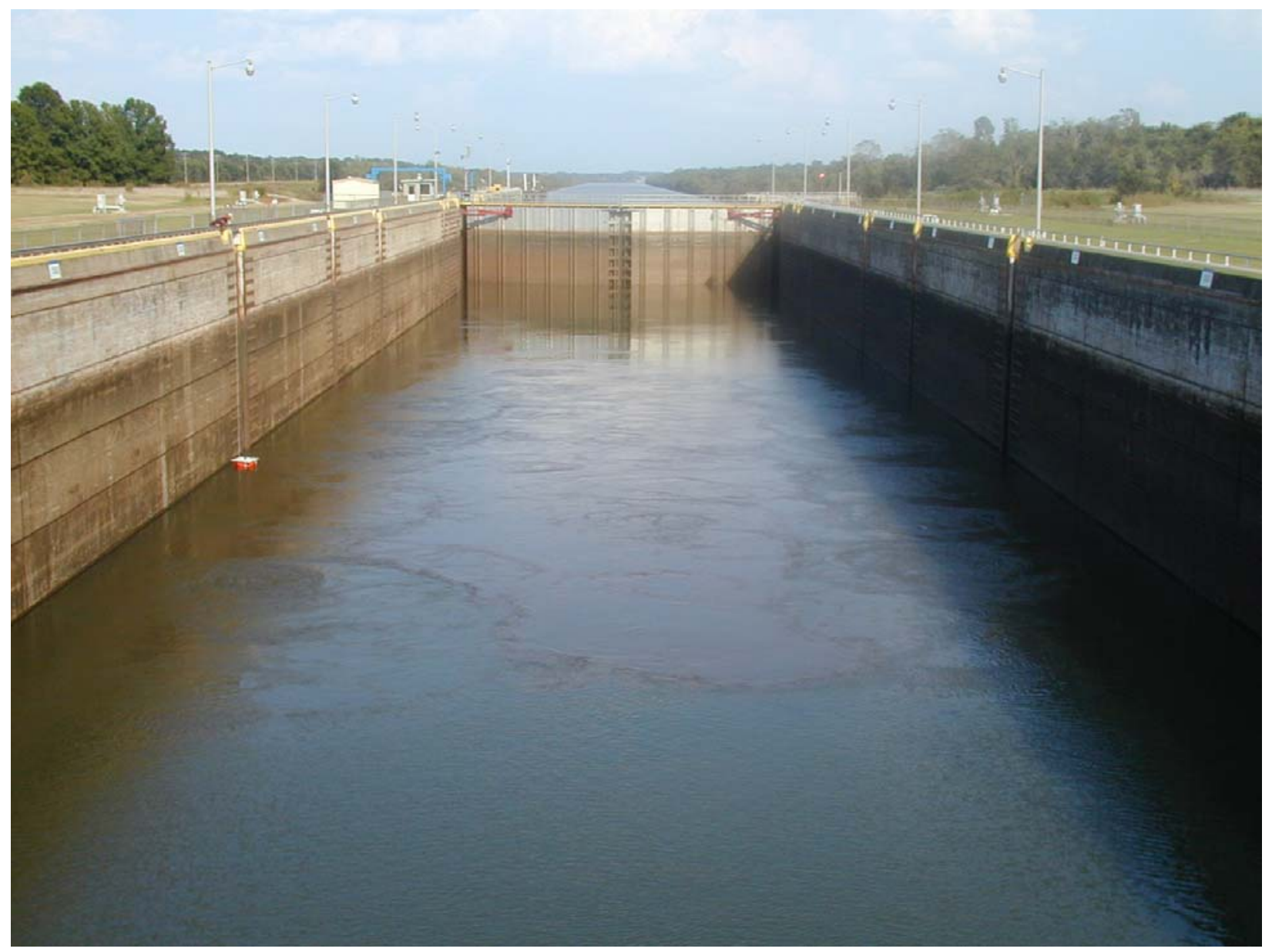

Figure 1. Lock chamber during filling operation.

\footnotetext{
${ }^{1}$ All elevations (el) cited herein are in feet referenced to the National Geodetic Vertical Datum (NGVD) (to convert feet to meters, multiply number of feet by 0.3048 )
} 


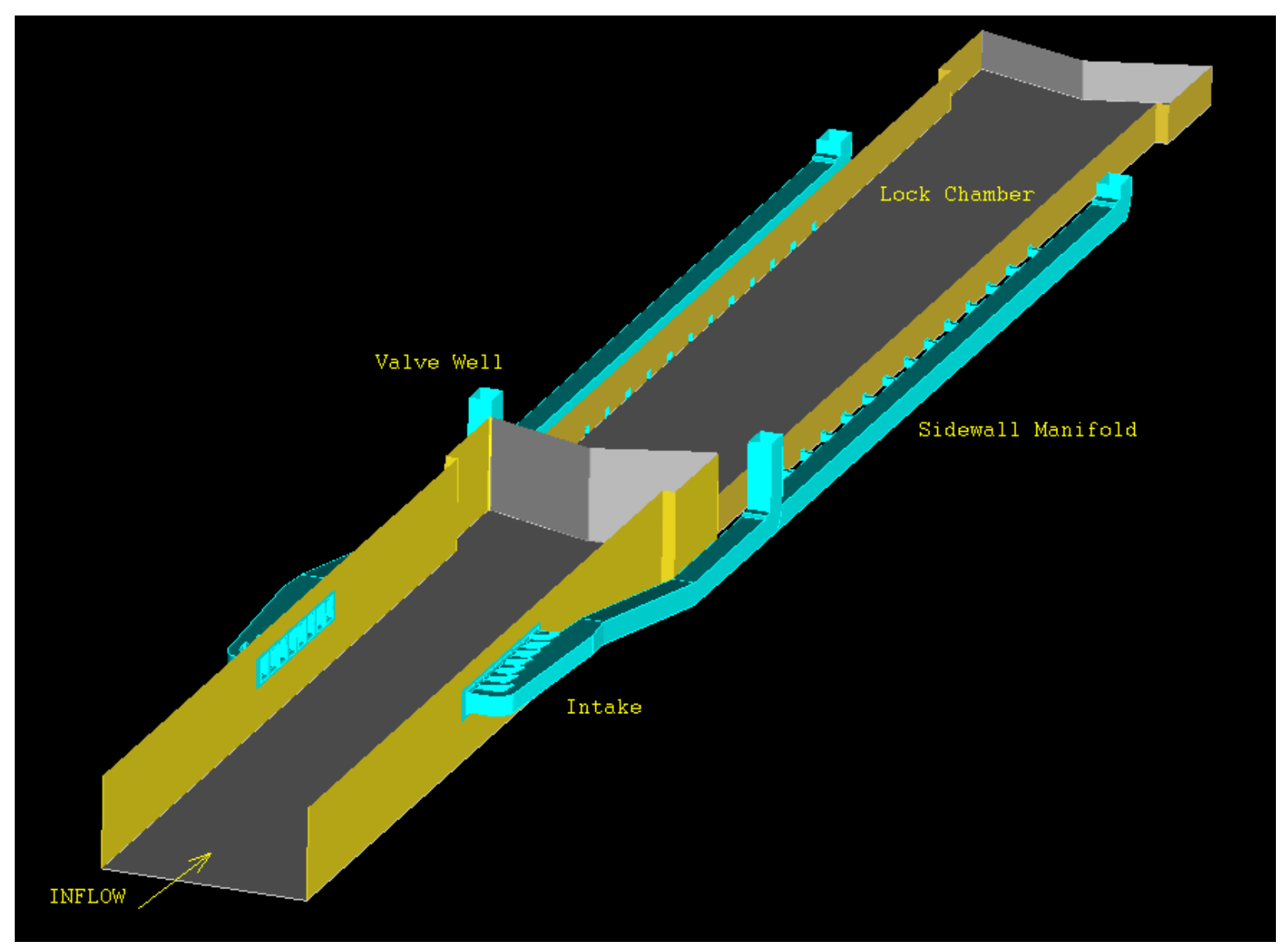

Figure 2. CAD model of Webbers Falls Lock filling system.

The finite element mesh had 229,090 nodes and 1,126,845 tetrahedral elements. The mesh resolution is illustrated by the surface mesh shown in Figure 3. Details of the mesh resolution at the intakes are shown in Figure 4 and of the filling and emptying manifold ports on the left culvert in Figure 5. The mesh defining the geometry with the right wall culvert and the filling and emptying ports is shown in Figure 6. A representative sample of the volume mesh is provided in Figure 7, wherein tetrahedral elements are shown on a slice normal to the lock center line from the right wall culvert through a filling and emptying port and into the lock chamber. Figure 7 illustrates the variation in mesh resolution required to describe the geometry. Flow variations are resolved during flow simulations using mesh adaption.

Steady Flow. The Webbers Falls Lock model was constructed to function as a steady-state or unsteady flow model. Steady flow through the filling system is achieved by setting the lower miter gates as an outflow boundary. Flow is pulled from the upper pool into the intakes and culvert system, discharged into the lock chamber, and then flows out the model through the lower end of the chamber. Steady flow is useful to determine head loss values of various system components. The steady-flow solution provides the pressure and velocity upstream and downstream of a particular component such as a valve well in a manner similar to that measured in a physical model study (e.g., Ables and Boyd 1966). 


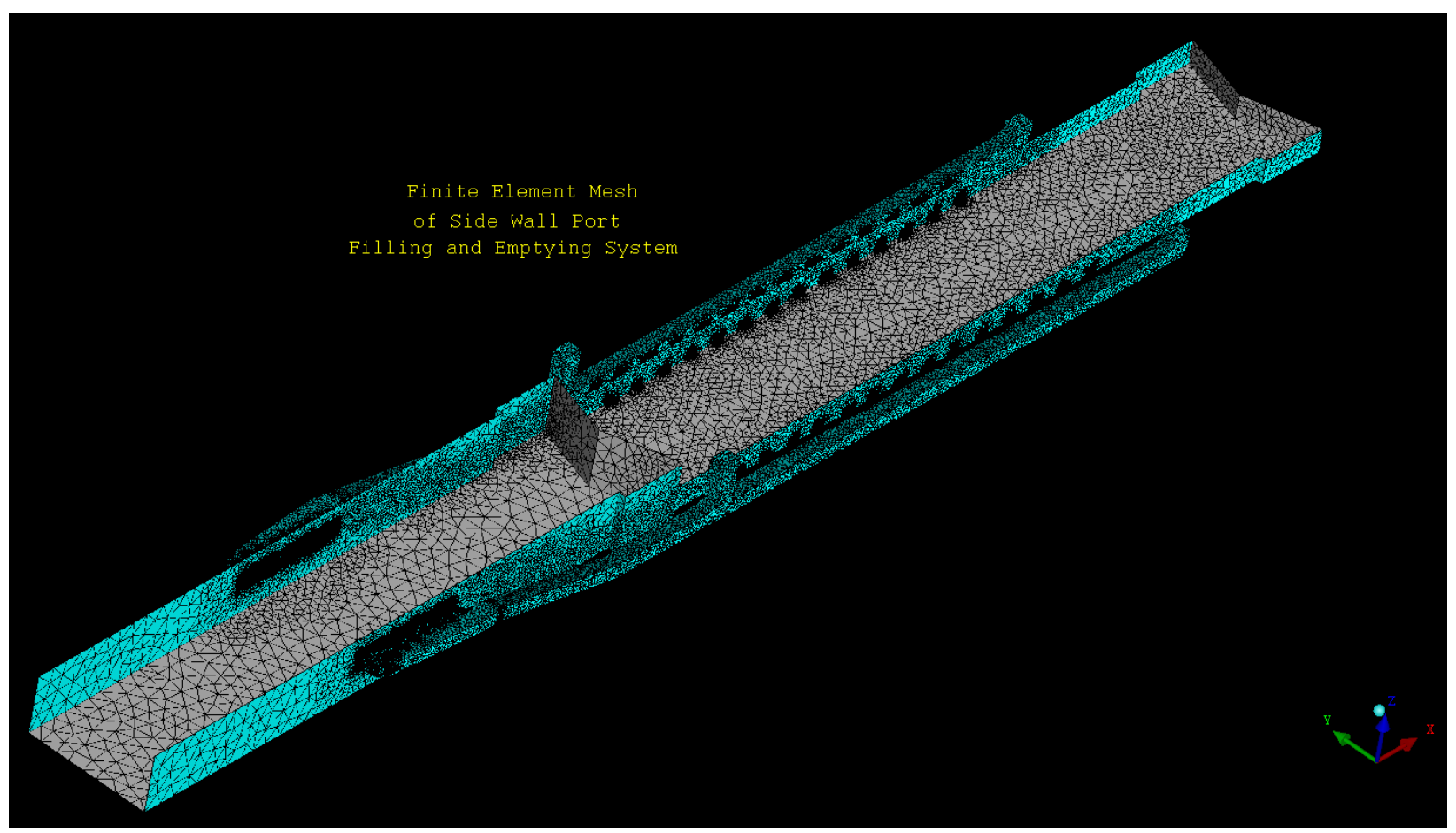

Figure 3. Computational surface mesh of lock filling system with water surface removed $(229,090$ nodes and 1,126,845 tetrahedral elements).

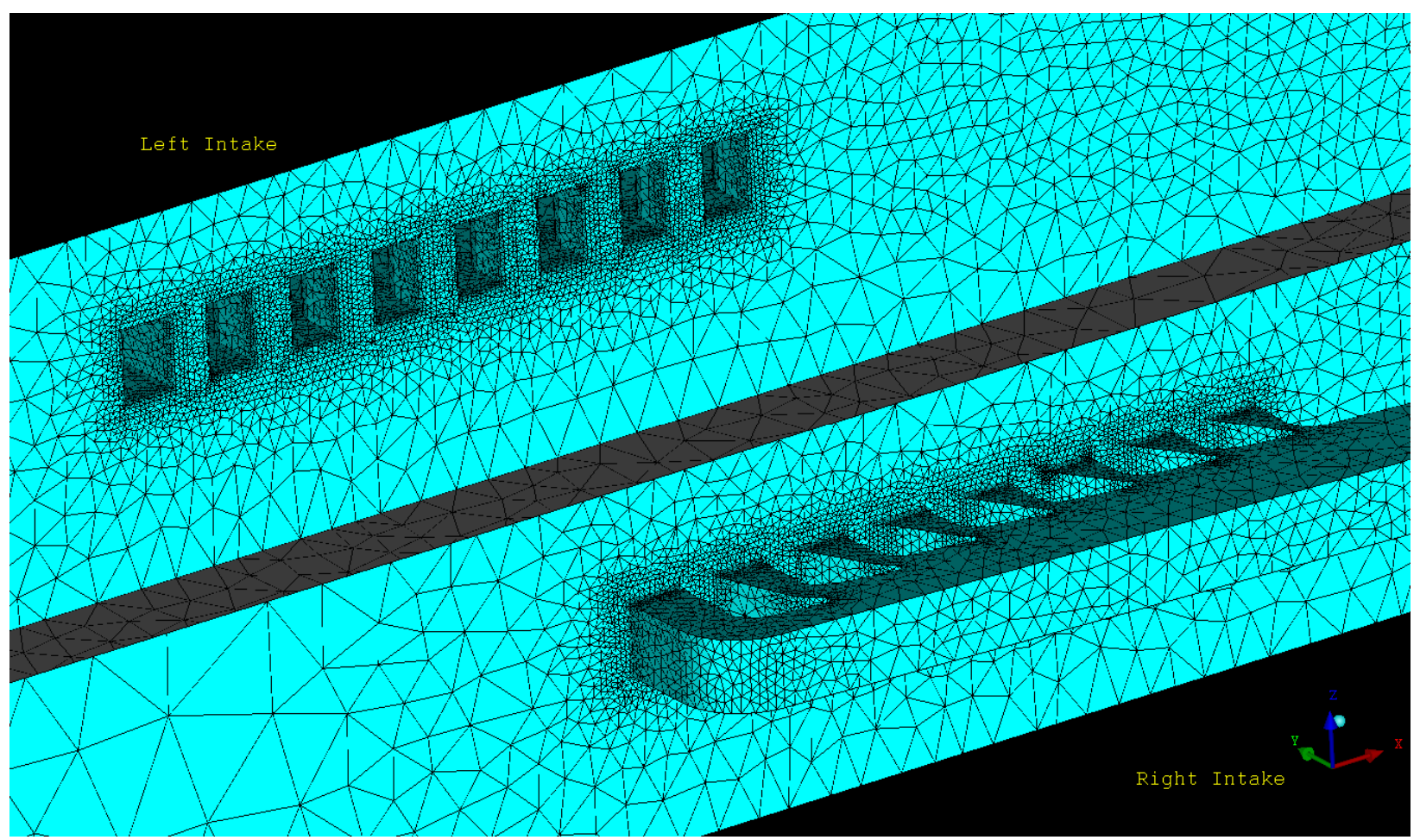

Figure 4. Details of surface mesh at intakes. 


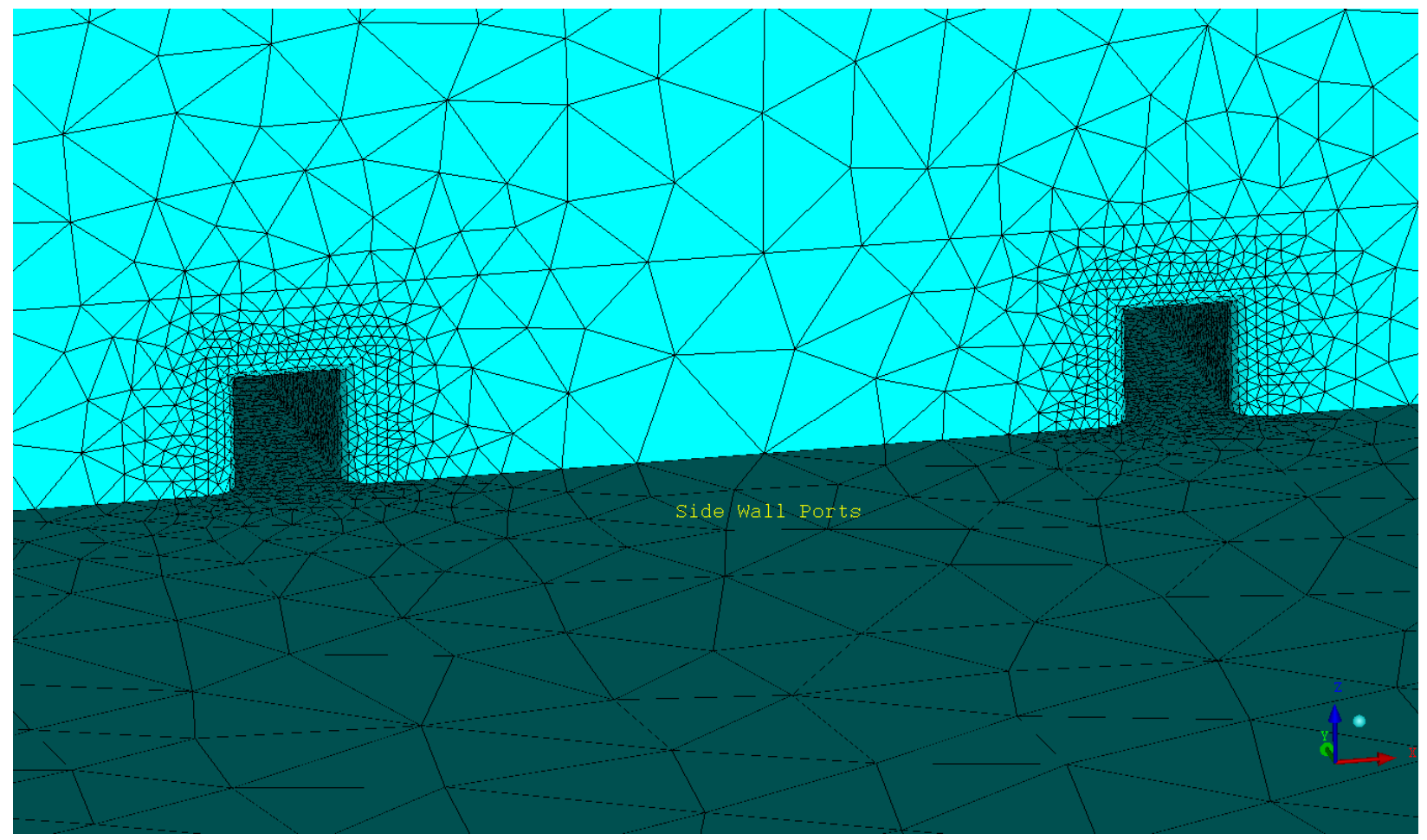

Figure 5. Surface mesh of port faces on lock chamber wall.

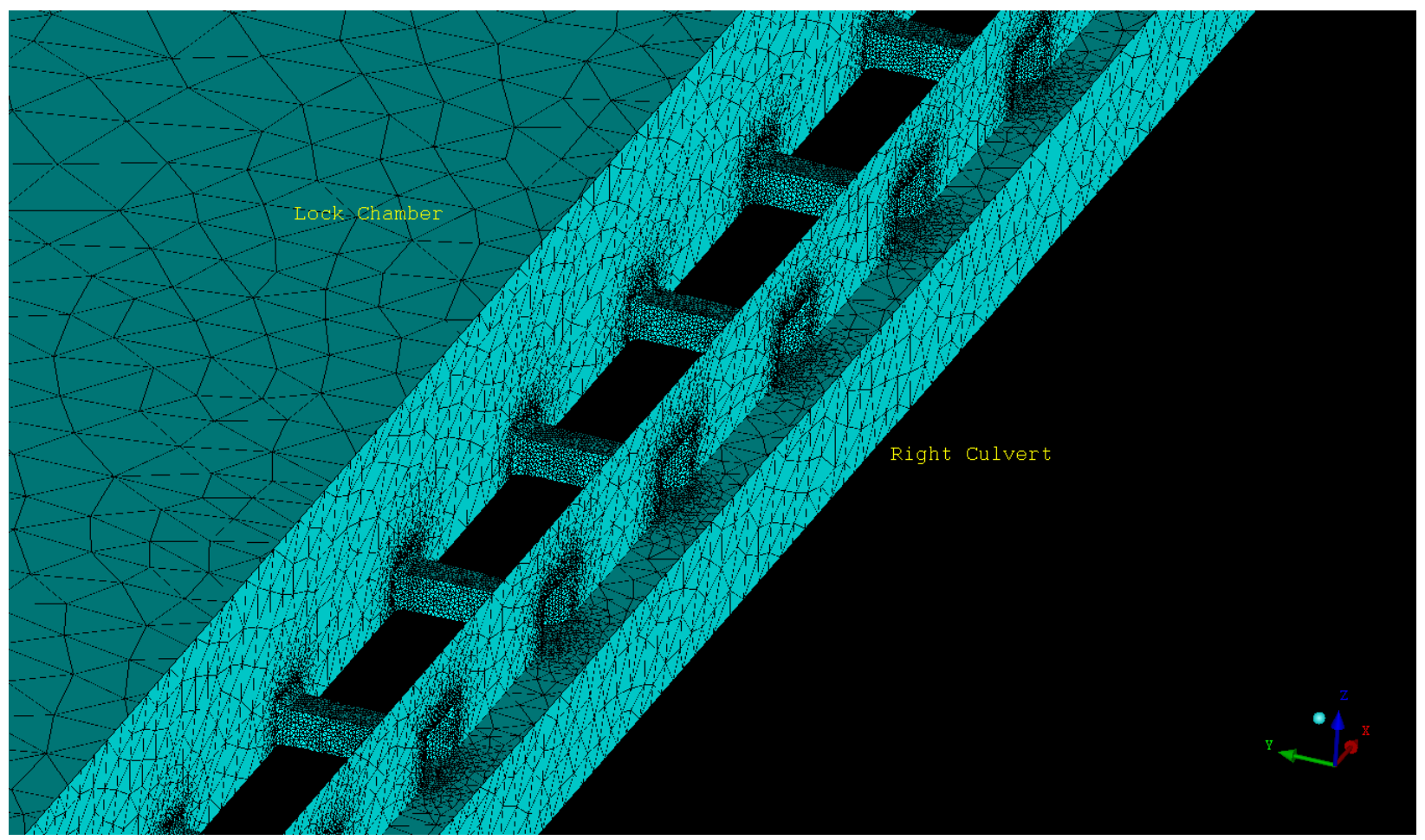

Figure 6. Surface mesh of right culvert and sidewall ports (culvert roof removed). 


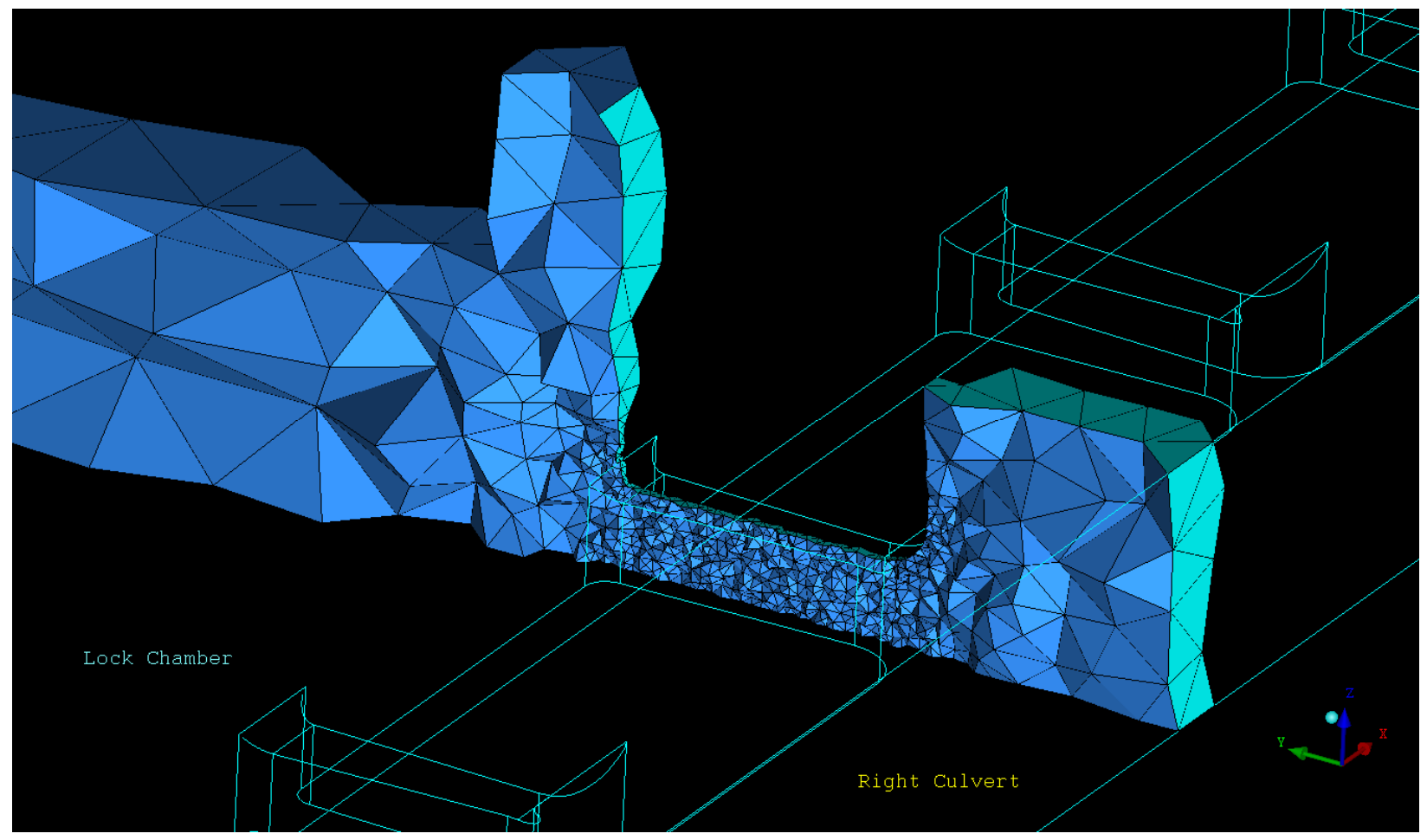

Figure 7. Volume mesh at section through the right culvert, sidewall port, and lock chamber.

The model was set up to simulate steady flow so that hydraulic coefficients particular to this lock filling system could be quantified. A flux boundary condition was set at the element faces on the upstream end of the model as the inflow and a hydrostatic pressure distribution was specified on the nodes of these faces. Outflow was through the faces making up the lower miter gates and the pressure at the nodes of these faces was set as hydrostatic. The upper pool was el 487 and the lock chamber was at el 458. Model parameters and hydraulic coefficients are listed in Table 1.

The steady-flow results are shown in Figures 8-11. Fig-

\begin{tabular}{|l|l||}
\hline \hline $\begin{array}{l}\text { Table } 1 \\
\text { Model parameters and hydraulic } \\
\text { coefficients, lock filling operation }\end{array}$ \\
\hline \hline $\begin{array}{l}\text { Model parameterl } \\
\text { Hydraulic coefficient }\end{array}$ & Value \\
\hline \hline Eddy Viscosity & $0.1 \mathrm{ft}^{2} / \mathrm{sec}$ \\
\hline Fluid density & $1.94 \mathrm{slugs} / \mathrm{ft}^{3}$ \\
\hline Friction coefficient & 0.003 \\
\hline Gravity & $32.2 \mathrm{ft} / \mathrm{sec}^{2}$ \\
\hline Pressure at free surface & 0.0 \\
\hline Time-step & $5.0 \mathrm{sec}$ \\
\hline Viscosity & $0.00001 \mathrm{ft}^{2} / \mathrm{sec}$ \\
\hline \hline
\end{tabular}
ure 8 illustrates the flow distribution through the system.

Figure 9 shows the flow distribution through the sidewall manifold. The stream traces show the path that a particular fluid particle would travel. The traces pass through points that are evenly distributed in each culvert $34 \mathrm{ft}$ upstream of the filling valves. The traces illustrate the roughness of the flow in the lock chamber. The upstream most intake port appears to not pass as much flow as the other ports. The head losses in the filling system can be quantified by the use of loss coefficients:

$$
K_{i}=\frac{H_{L i}}{V_{c}^{2} / 2 g}
$$




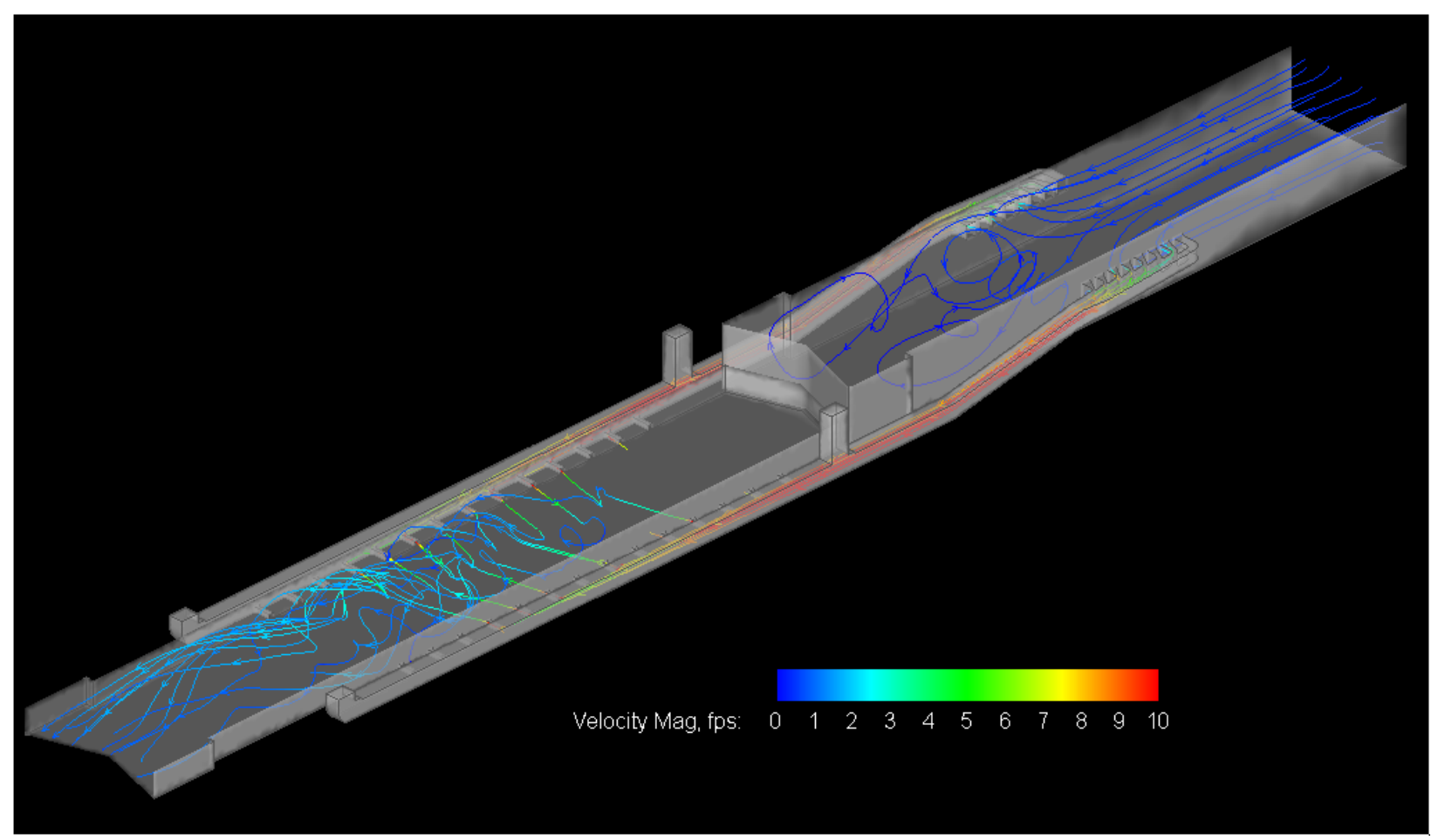

Figure 8. Stream traces in lock system under steady-flow conditions.

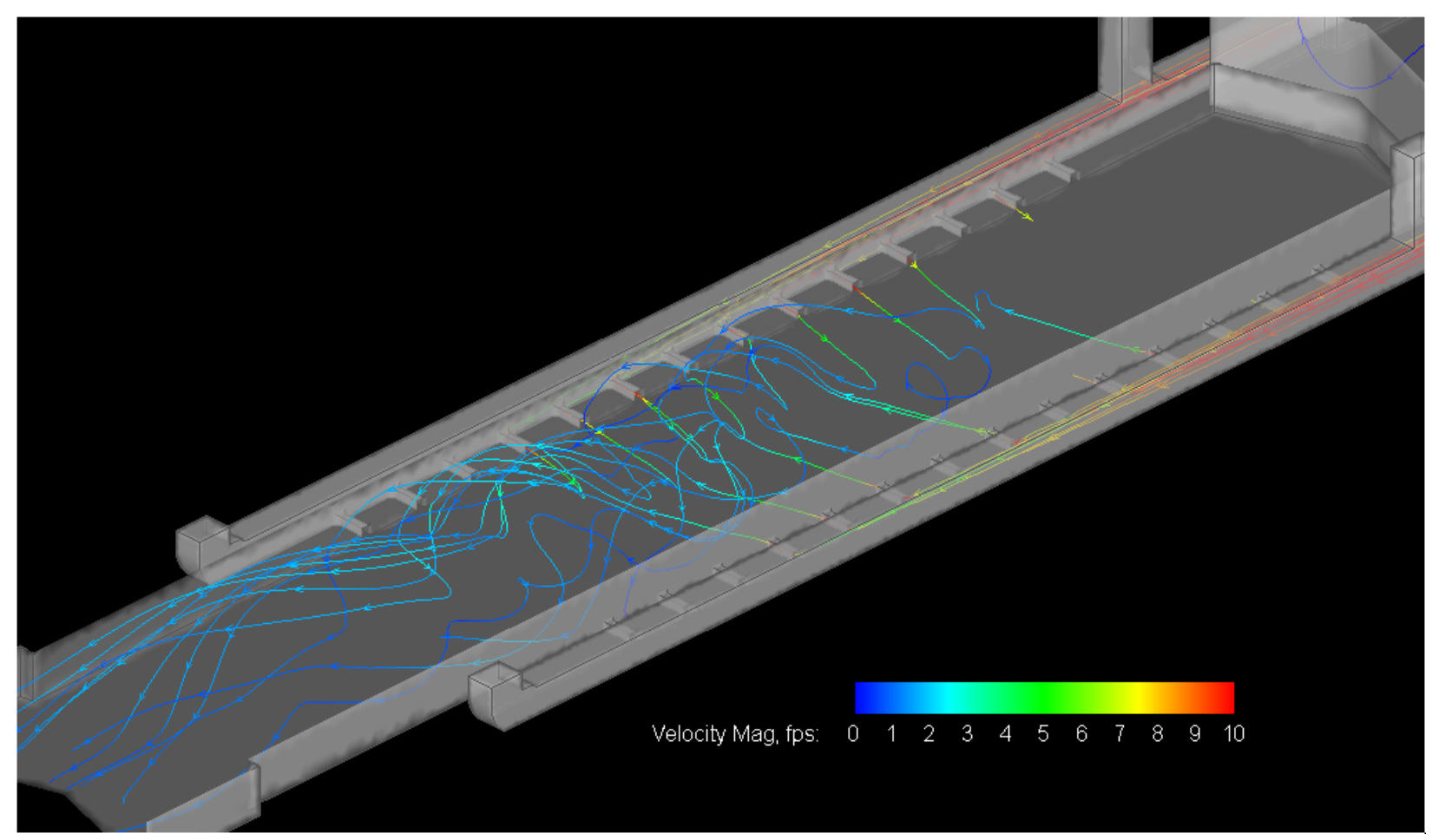

Figure 9. Stream traces in culvert and lock chamber under steady-flow conditions. 


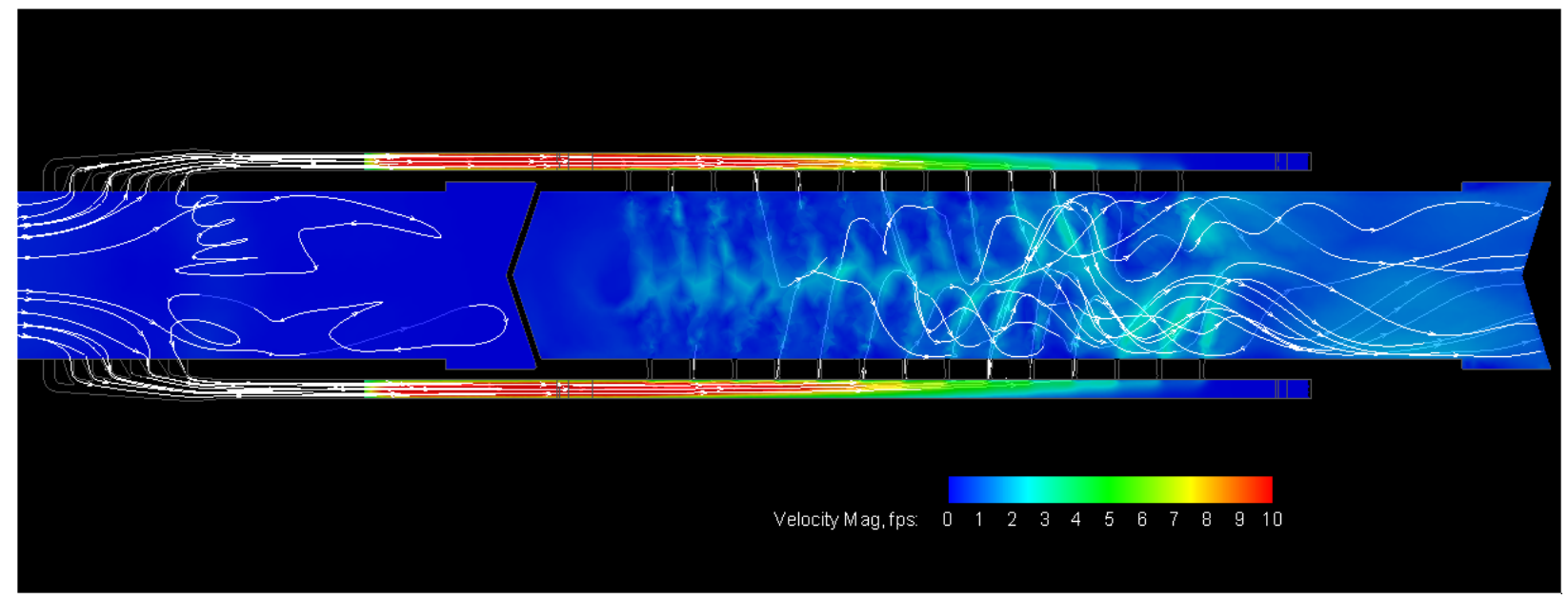

Figure 10. Velocity magnitude contours and stream traces at el 443 under steady-flow conditions (flow is from left to right).

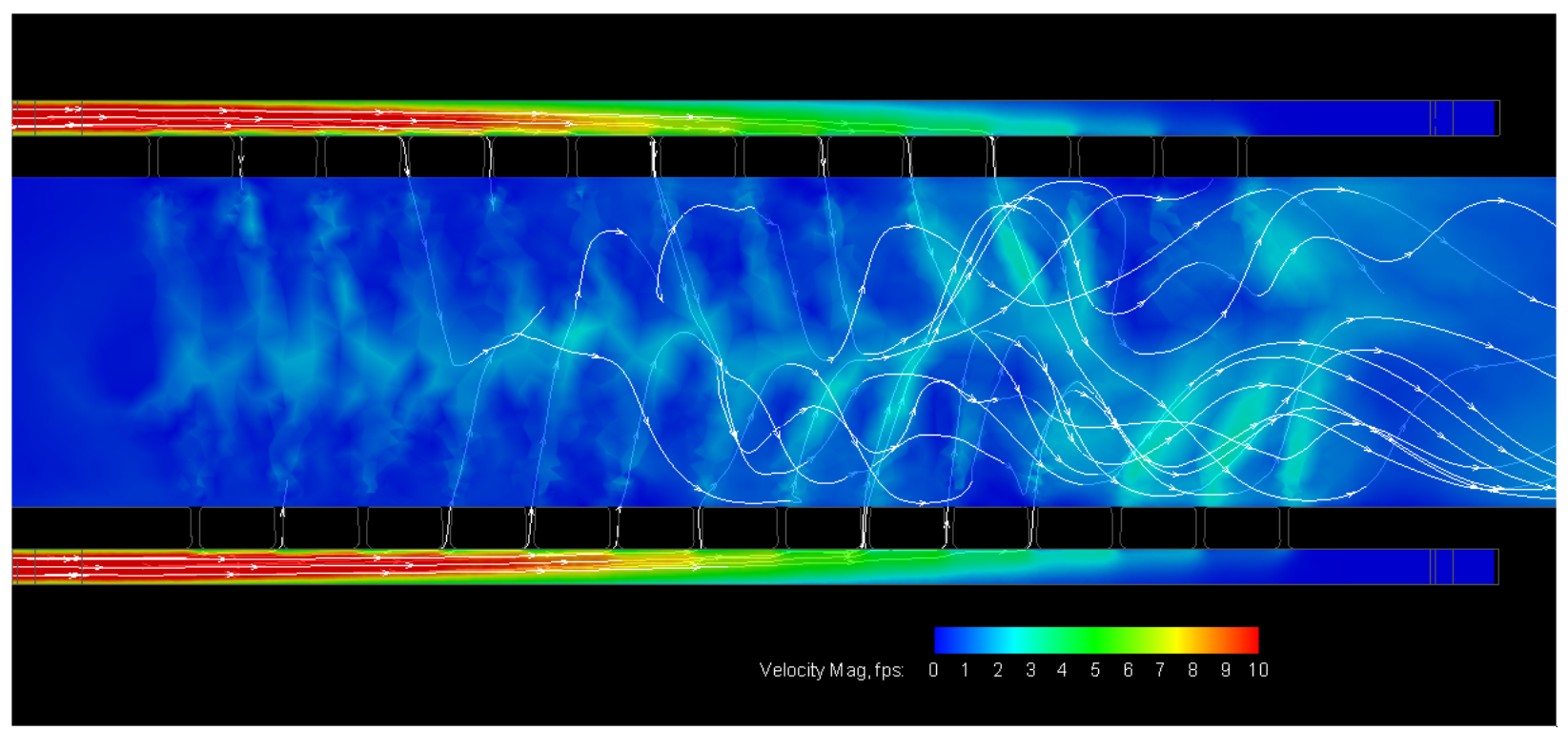

Figure 11. Velocity magnitude contours and stream traces in lock chamber and culvert at el 443 under steady-flow conditions.

where

$$
\begin{aligned}
& K_{i}=\text { component loss coefficient } \\
& H_{L i}=\text { head loss through component } i \\
& V_{c}=\text { average culvert velocity at the valve }
\end{aligned}
$$

Loss coefficients for the intake manifold, the filling valve well, and the sidewall culvert manifold were computed from the steady-flow pressures and velocities. Loss coefficients for the filling system are listed in Table 2. A direct comparison with physical model data is not possible because prototype design modifications were made to the designs tested by Ables and Boyd 
(1966). However, comparisons can be made with the general values given by Murphy (1975) for sidewall port filling systems.

The computed discharge through the filling system was $10,900 \mathrm{cfs}$. This discharge results in an average velocity of 37.85 fps at the valve and a velocity head at the valve of $22.24 \mathrm{ft}$. The total loss coefficient of 1.26 corresponds to a lock coefficient of 0.89 (see EM 1110-2-1604 for explanation of lock coefficient). Murphy (1975) reports that 0.80 is a reasonable value for the lock coefficient of a sidewall port lock filling system. The coefficients derived from the simulation results differ from the design values given by Murphy (1975). In particular, the mani-

\section{Table 2 Head loss coefficients for lock filling system}

\begin{tabular}{||l|l|l||}
\hline \multirow{2}{*}{ Component } & \multicolumn{2}{|c|}{$\begin{array}{r}\text { Component Loss } \\
\text { Coefficient, } \mathrm{K}_{\mathbf{i}}\end{array}$} \\
\cline { 2 - 3 } & $\begin{array}{l}\text { Murphy } \\
(\mathbf{1 9 7 5 )}\end{array}$ & $\begin{array}{l}\text { Simulation } \\
\text { Results }\end{array}$ \\
\hline \hline $\begin{array}{l}\text { Upper pool to } \\
\text { valve }\end{array}$ & 0.45 & 0.25 \\
\hline $\begin{array}{l}\text { Through open } \\
\text { valve }\end{array}$ & 0.10 & 0.18 \\
\hline $\begin{array}{l}\text { Valve to lock } \\
\text { chamber }\end{array}$ & 1.05 & 0.83 \\
\hline Total & 1.60 & 1.26 \\
\hline
\end{tabular}
fold losses are too small. Perhaps this is due to error in the computed turbulent stresses. The energy losses in the lock chamber that are attributed to expansion of the port jets are difficult to simulate. Future efforts will be directed toward evaluating the turbulence model for the ADH code.

Unsteady Flow - Lock Filling. The initial conditions for simulation of a lock filling operation were set with the lock empty and the chamber water surface at el 458. Zero velocity and hydrostatic pressure were specified at each node. The inflow hydrograph varied linearly increasing from no flow at the initial time up to the peak discharge of 5,088 cfs at 4 min and then decreasing to zero at time equal to $10 \mathrm{~min}$. This hydrograph fills the lock chamber in $10 \mathrm{~min}$.

A no flux boundary condition was applied at all solid boundaries. The free surface within the lock chamber was set as a moving boundary while those other than the chamber (culvert, intakes, etc.) were fixed boundaries. The nodes within the chamber volume were allowed to move in the vertical direction. Nodes not on the water surface moved as a function of surface node displacements. For this example the nodes on a horizontal plane in the lock chamber at el 443.5 were fixed (no displacement) thus preserving the complicated geometry of the manifolds that lie beneath el 443.5. Nodes along the sides of the chamber were allowed to displace vertically along the boundary.

At the moving boundary representing the water surface, a constant Dirichlet condition for the pressure and stress-free conditions for the tangential components of stress were specified. Zero was specified as the pressure at the free surface. Model parameters and hydraulic coefficients were the same as those used for the steady-flow simulation (Table 1) except the time-step was reduced to $0.1 \mathrm{sec}$.

Flow variations within the chamber during filling (Figure 12-16) show velocity contours and vectors at particular times during the simulation. The lock chamber water surface rises from the lower pool of el 458 (initial conditions) to the upper pool of el 487 as the lock fills. The jets issuing from the manifolds $1 \mathrm{~min}$ after filling started are shown in Figure 17. These velocity contours provide an insightful view of the flow distribution and jet interaction in the culvert manifold and chamber. 


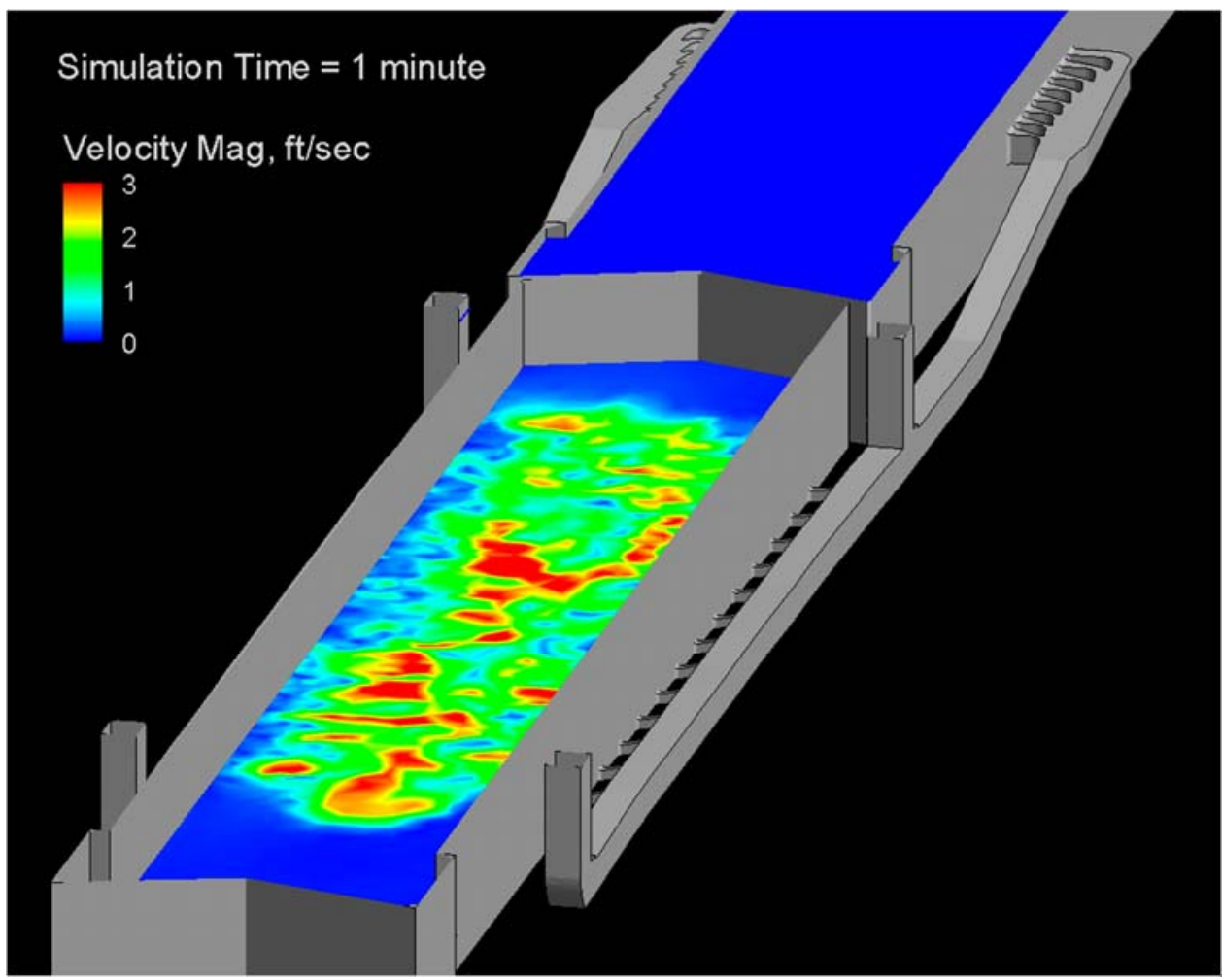

Figure 12. Velocity magnitude contours in lock chamber 1 min after filling started.

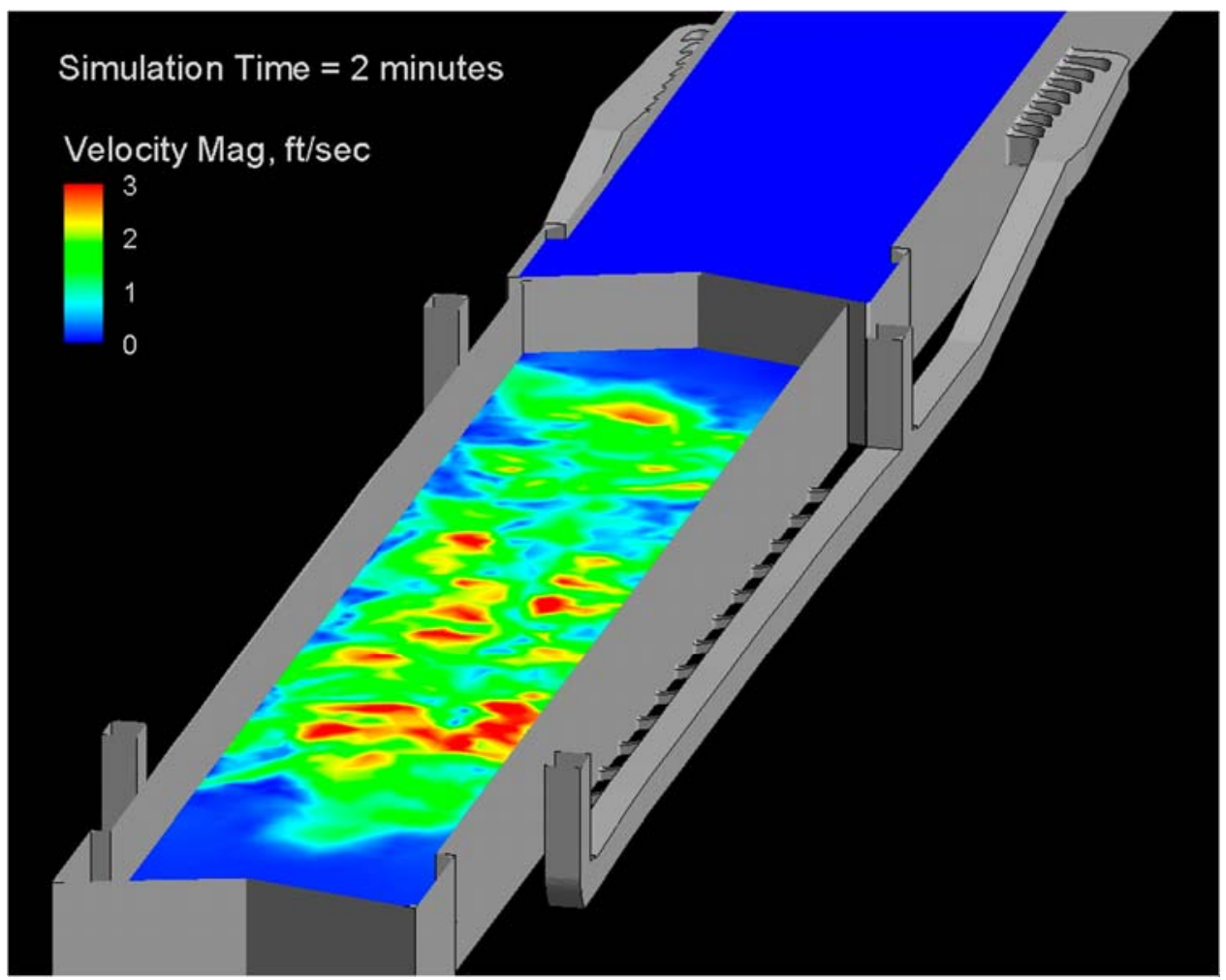

Figure 13. Velocity magnitude contours in lock chamber 2 min after filling started. 


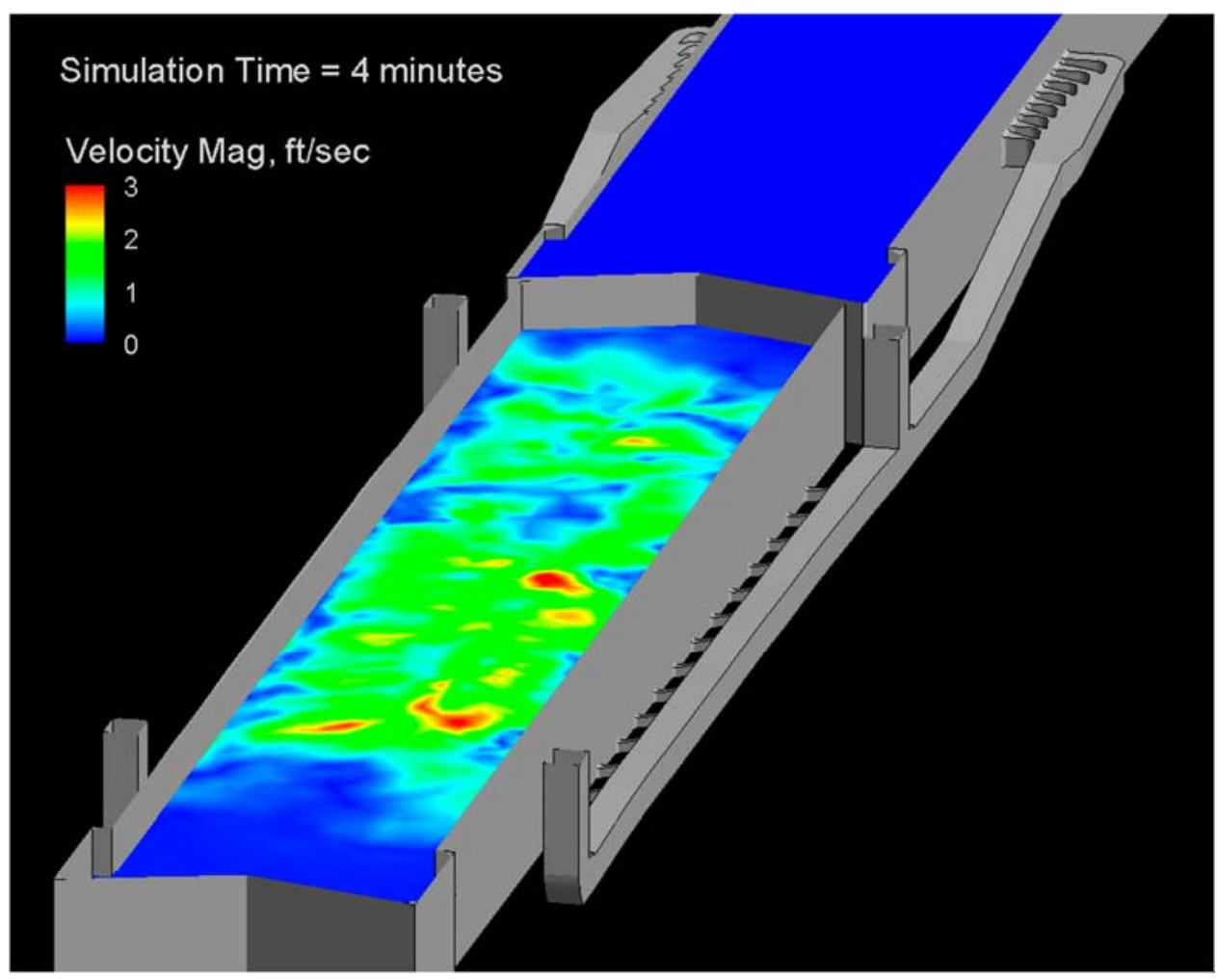

Figure 14. Velocity magnitude contours in lock chamber 4 min after filling started.

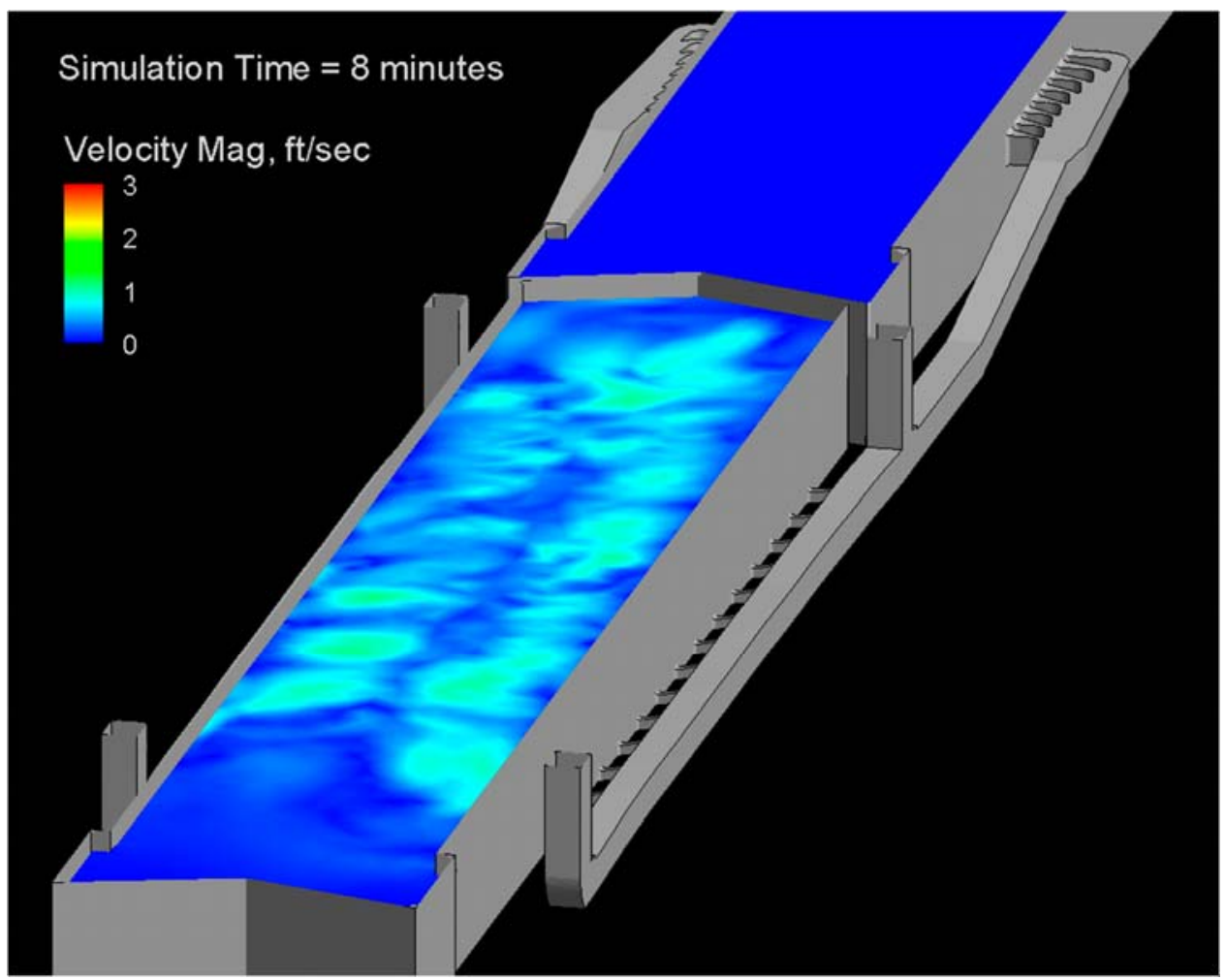

Figure 15. Velocity magnitude contours in lock chamber 8 min after filling started. 


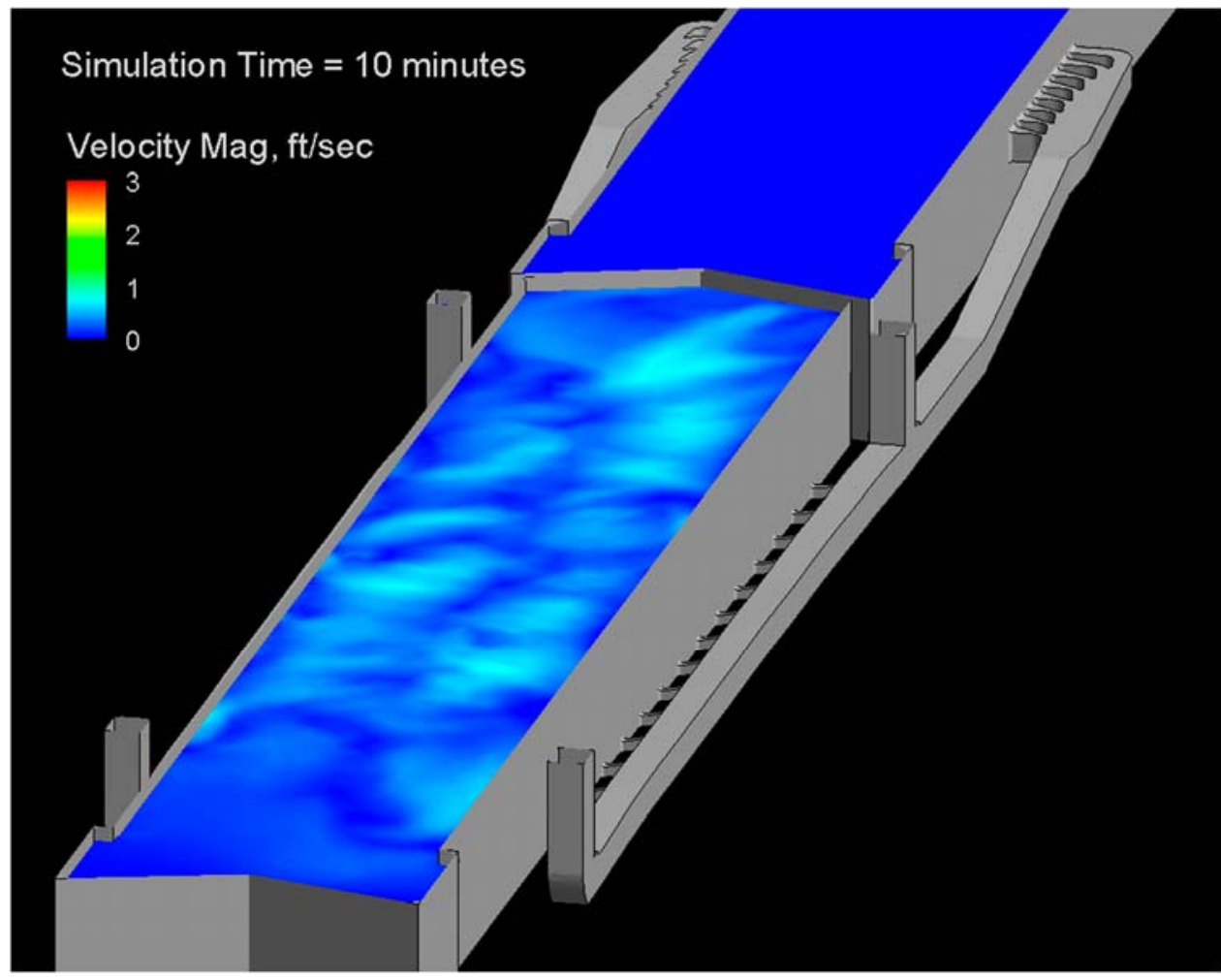

Figure 16. Velocity magnitude contours in lock chamber 10 min after filling started.

Filling time $=1 \mathrm{~min}$

Contours at elev. $439 \mathrm{ft}$

$\begin{array}{llllllllllllllll}\text { Velocity Mag, ft/sec: } & 2 & 4 & 6 & 8 & 10 & 12 & 14 & 16 & 18 & 20 & 22 & 24 & 26 & 28 & 30\end{array}$

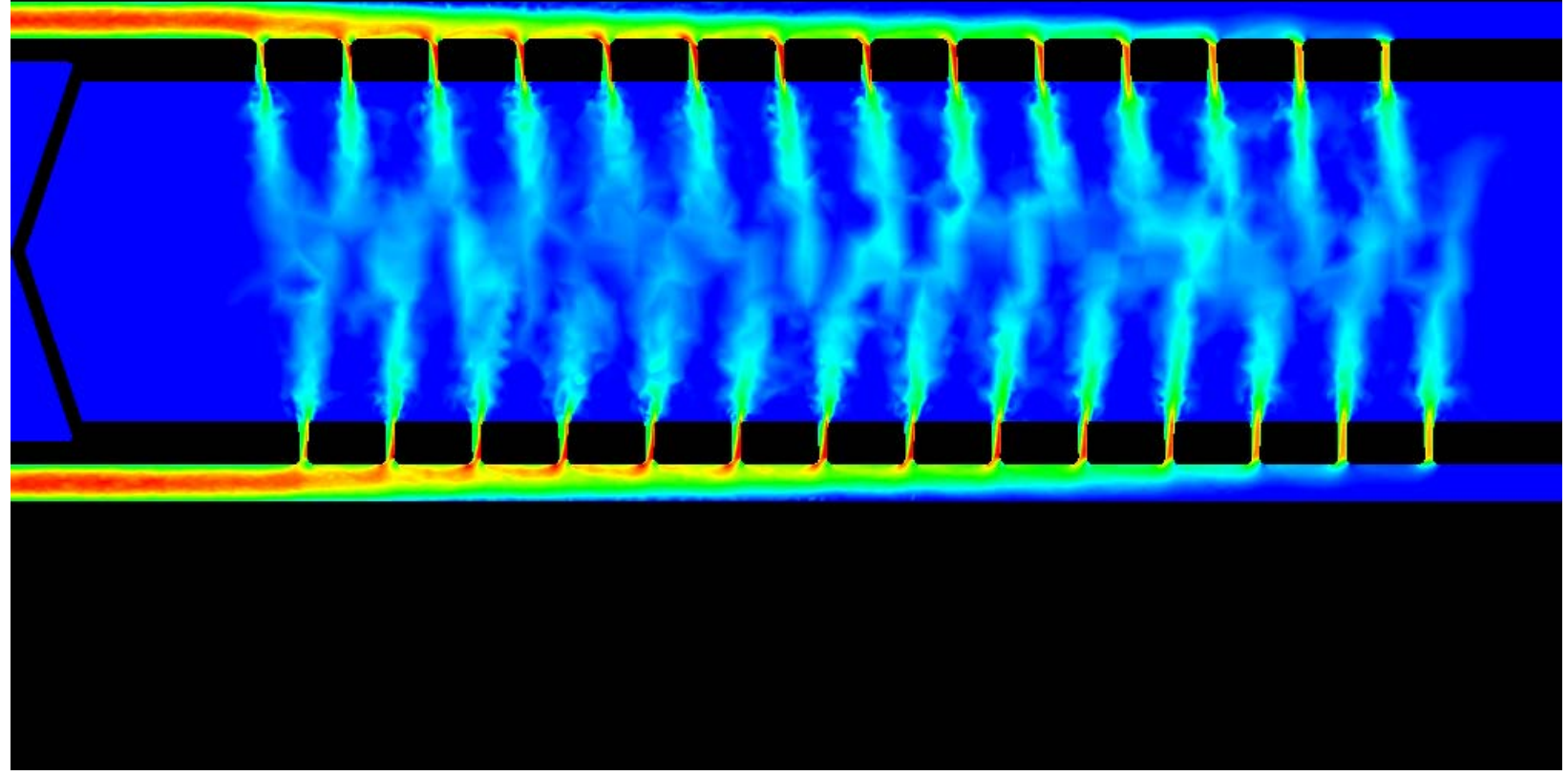

Figure 17 . Velocity magnitude contours showing flow in each sidewall manifold and lock chamber. 
The filling curves for the upstream and downstream ends of the chamber are provided in Figure 18. The immediate rise of the water surface as filling begins is due to the specified inflow. As previously mentioned, the specified (hypothetical) inflow increased linearly for the first 4 min. The flow in a real lock system is throttled by the culvert valves, which results in a smaller rate-of-rise during the early portion of the filling operation. Due to acceleration and the valve movement, the filling rate varies in a nonlinear fashion in a real system. As the valves open, the real system experiences a rate-of-rise that is near linear, which means that the discharge variation with respect to time is almost quadratic. Simulation of moving mechanical components is a model feature that will be added in the future.

Lock chamber performance is evaluated using the slope of the water surface since it is directly proportional to the hawser forces. The chamber water-surface slope is plotted in Figure 19. A positive slope on the graph indicates that the water-surface elevation at upstream end of the lock chamber is higher than that at the downstream end. The recommended maximum hawser force of 5 tons is equivalent to a water-surface slope of $0.32 \mathrm{ft} / 1,000 \mathrm{ft}$ for an 8-barge tow with 15,530 tons of displacement. This is exceeded during the first 4 min after filling starts with this hypothetical filling hydrograph.

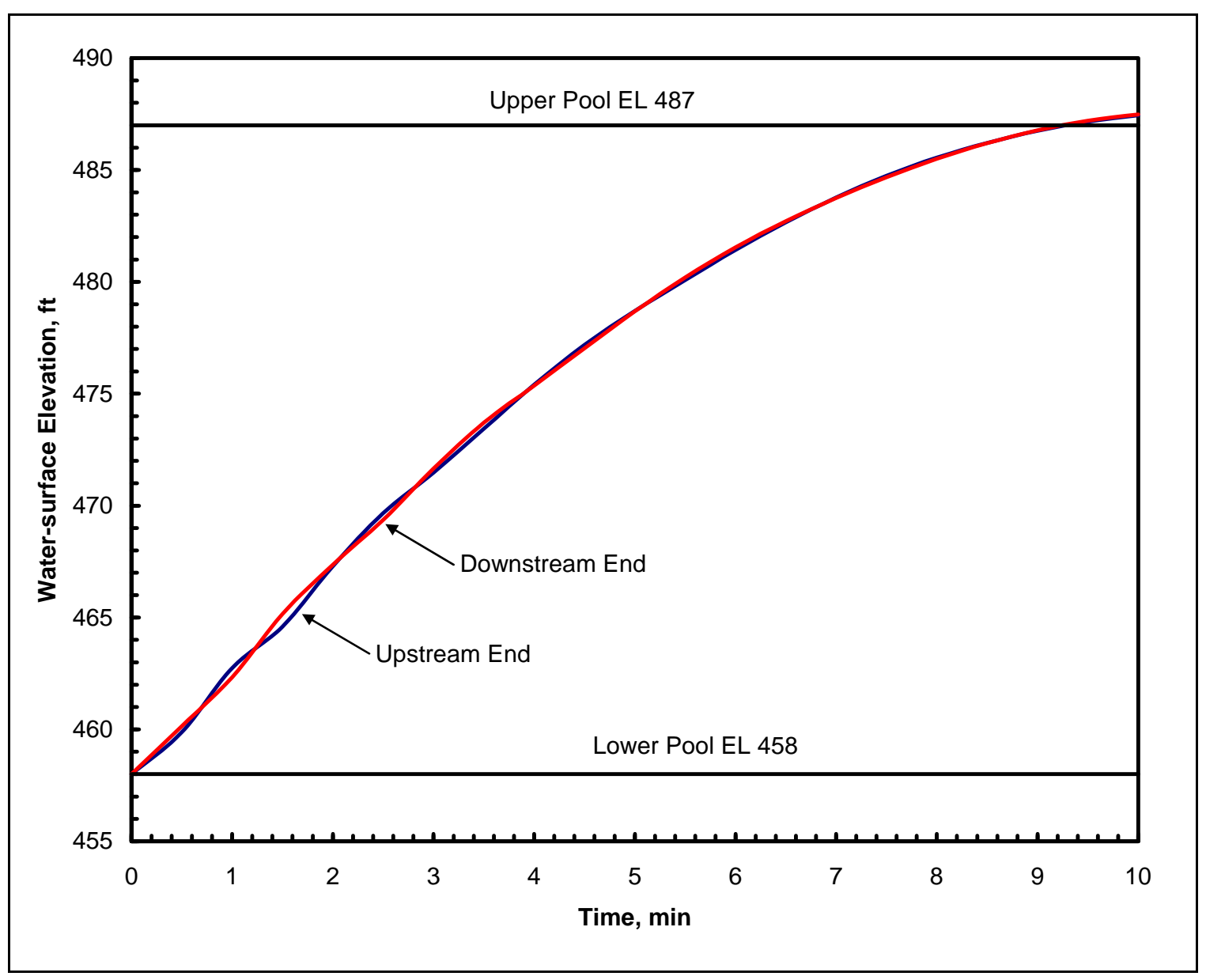

Figure 18. Lock filling curve. 


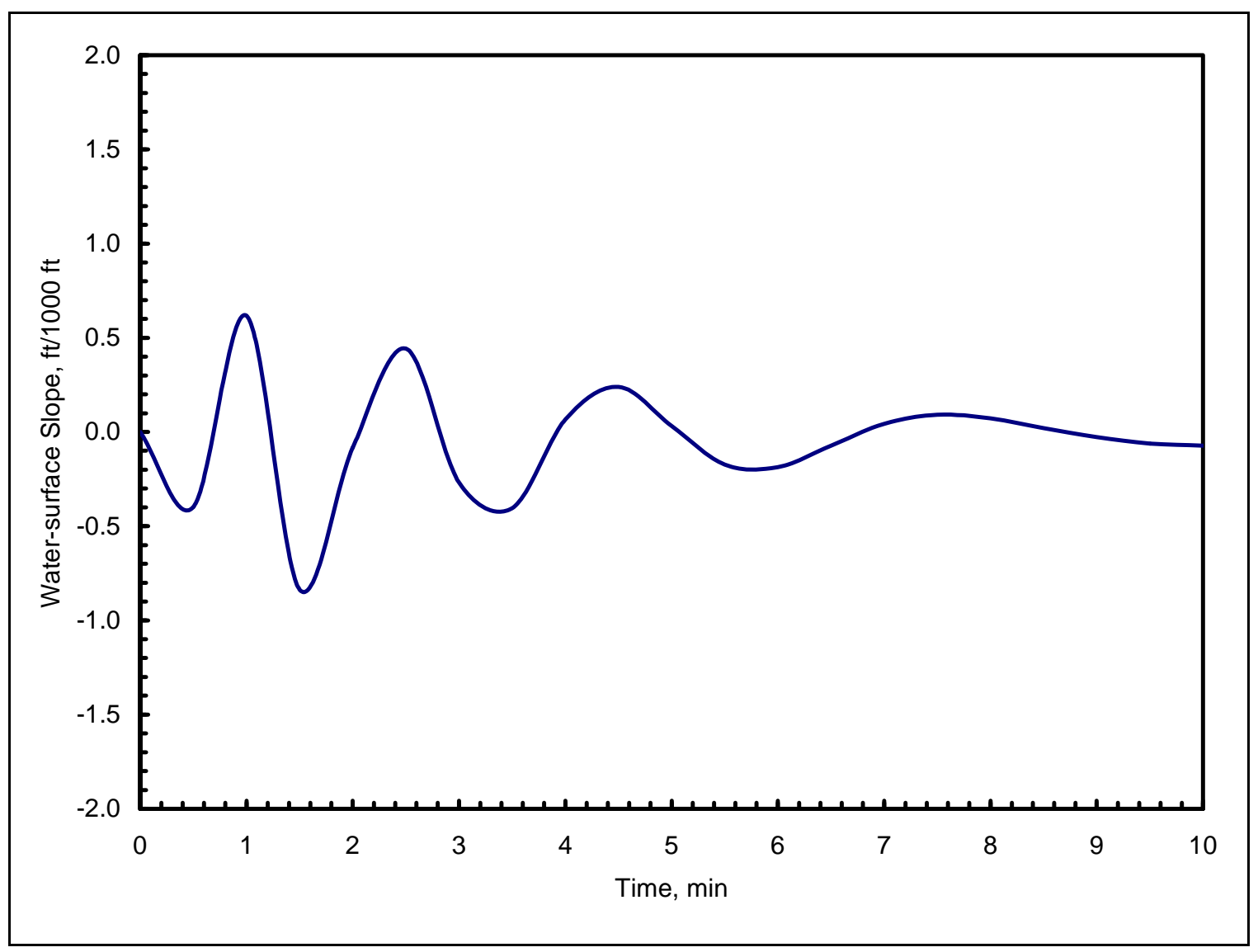

Figure 19. Water-surface slope within lock chamber during filling.

COMPUTATIONAL ISSUES: Simulation of the lock chamber filling uses a moving mesh method that is complicated by the fact that the tetrahedral elements might become ill-formed as the simulation progresses. Even if the elements are not sheared or inverted, deterioration of quality from excessive skewness can reduce the matrix solver's efficiency. So the idea is to maintain a certain level of mesh smoothness. In order to maintain mesh quality, the mesh motion must be limited to small displacements or occasional remeshing.

Successful modeling of a lock operation requires the ability to include the effects of moving components such as valves and gates. This can be treated using a moving mesh method similar to that used for the free surface except the movement specified a priori. Moving the mesh to track the movement of a valve will probably require frequent remeshing.

SUMMARY: This study has investigated the process of constructing a complete 3-D finite element model of a sidewall port lock filling system. The project was a model of Weber Falls Lock, Arkansas River. This exercise demonstrated model construction capability and led to improved ways of developing a lock filling and emptying system model having such complicated geometric details (ports, culverts, manifolds, etc).

There is a need for moving mechanical components such as valves. Inertia and the losses due to an opening valve are critical to accurate simulation of lock performance. 
FUTURE WORK: Additional testing will quantify the accuracy of simulating lock culvert flow (pressures, velocity profile, etc.) and lock chamber flow conditions (jet expansion, movement of free surface, etc.). A proper turbulence model is required to accurately capture flow details such as jet expansion rate. The ADH code will be extended to simplify and enhance the turbulence modeling capabilities. Also, a means of including the effects of flow control devices such as culvert valves will be added. Representation of moving mechanical equipment such as valves and gates must be added to the code before a full lock model study can be completed. Finally, the capability of modeling a vessel moored in the chamber during locking operations will be developed. A modeling system that accounts for a barge/ship in the lock chamber and that can calculate hawser forces during locking operations will be constructed.

POINTS OF CONTACT: This CHETN is a product of the Computational Lock Model work unit of the Navigation Systems Research Program (Nav Sys) being conducted at the U.S. Army Engineer Research and Development Center, Coastal and Hydraulics Laboratory. Questions about this technical note can be addressed to Dr. Richard L. Stockstill (Voice: 601-634-4251, Fax: 601-634-3218, e-mail: Richard.L.Stockstill@usace.army.mil). For information about the Navigation Systems Research Program (Nav Sys), contact the Program Manager, James E. Clausner at 601-634-2009, e-mail: James.E.Clausner@usace.army.mil. This CHETN should be cited as follows:

Stockstill, R. L. 2009. Computational model of a lock filling system. Coastal and Hydraulics Engineering Technical Note ERDC/CHL CHETN-IX-18. Vicksburg, MS: U.S. Army Engineer Research and Development Center. http://chl.erdc.usace.army.mil/chetn

\section{REFERENCES}

Ables, J. H., and M. B. Boyd. 1966. Filling and emptying system low-lift locks Arkansas River Project, hydraulic model investigation. Technical Report No. 2-743. Vicksburg, MS: U.S. Army Engineer Waterways Experiment Station.

Behr, M. 2001. Stabilized space-time finite element formulations for free-surface flows. Communications in numerical methods in engineering 17(11):813-819.

Headquarters, U.S. Army Corps of Engineers. 2006. Hydraulic design of navigation locks. Engineer Manual No. 1110-2-1604. Washington, DC: Headquarters, U.S. Army Corps of Engineers.

Murphy, T. E. 1975. Lock design, sidewall port filling and emptying system. Miscellaneous Paper H-75-7. Vicksburg, MS: U.S. Army Engineer Waterways Experiment Station.

Stockstill, R. L., and R. C. Berger. 2000. Simulation of flow in hydraulic structures using ADH. ERDC/CHL CHETN-IX-4, Vicksburg, MS: U.S. Army Engineer Research and Development Center.

Stockstill, R. L., J. E. Hite, and J. M. Vaughan. 2005. Computational model of Ice Harbor forebay, Washington. ERDC/CHL TR-05-5. Vicksburg, MS: U.S. Army Engineer Research and Development Center.

Stockstill, R. L., C. E. Kees, and R. C. Berger. 2006. Modeling free-surface flow over a weir. ERDC/CHL CHETNXIII-1, Vicksburg, MS: U.S. Army Engineer Research and Development Center. 
Tate, J. N., R. C. Berger, and R. L. Stockstill. 2005. Refinement indicator for mesh adaption in shallow-water modeling. Journal of Hydraulic Engineering 132(8):854-857.

NOTE: The contents of this technical note are not to be used for advertising, publication, or promotional purposes. Citation of trade names does not constitute an official endorsement or approval of the use of such products. 